\title{
Effect of IL-17 monoclonal antibody Secukinumab combined with IL-35 blockade of Notch signaling pathway on the invasive capability of hepatoma cells
}

\author{
H.CH. Li ${ }^{1,2}$, Y.X. Zhang', Y. Liu ${ }^{3}$ and Q.SH. Wang ${ }^{1}$ \\ ${ }^{1}$ Department of PET Center, Southern Hospital, Southern Medical University, \\ Guangzhou, China \\ ${ }^{2}$ Department of Ultrasound, \\ The First Affiliated Hospital of Inner Mongolia Medical University, \\ Hohhot, China \\ ${ }^{3}$ Department of Ultrasound, PLA 302 Hospital, Beijing, China \\ Corresponding author: Q.SH. Wang \\ E-mail: lihaochangnmg12@163.com \\ Genet. Mol. Res. 15 (2): gmr.15028174 \\ Received November 27, 2015 \\ Accepted January 18, 2016 \\ Published July 15, 2016 \\ DOI http://dx.doi.org/10.4238/gmr.15028174
}

\begin{abstract}
We investigated the effect of the IL-17 monoclonal antibody Secukinumab combined with IL-35 in the blockade of the Notch signaling pathway on the invasive capability of hepatoma cells. We examined the effects of IL-17 antibody or IL-35 treatment alone or in combination on cell invasion and migration capabilities with Transwell chambers. The mRNA levels of Hes1, Hes5, and Hey1 were tested using quantitative polymerase chain reaction. The protein expression of N1ICD, Snail, and E-cadherin protein expressions were measured with western blot. The expression of Hes1, Hes5, Hey1 and N1ICD were all very high in hepatoma cell lines, and were positively correlated with the invasive migration capabilities of the cells. The combination of IL-17 monoclonal antibody Secukinumab with IL-35 could effectively inhibit the Notch signaling pathway, as well as the invasive migration of the cells. Snail and E-cadherin are involved in the migration of hepatoma
\end{abstract}


cells, and it has been established that Snail can regulate the expression of E-cadherin. IL-17 monoclonal antibody Secukinumab combined with IL-35 can increase E-cadherin and decrease Snail expression, which are positively correlated with cell invasive migration capabilities. Overall, treatment with both IL-17 antibody and IL-35 is more effective than each treatment alone. Notch signaling is activated in hepatoma cell lines and increases with the enhancement of cell invasive migration capabilities. IL-17 monoclonal antibody Secukinumab combined with IL-35 can block the Notch signaling pathway, simultaneously reducing the invasive migration capability of hepatoma cells.

Key words: IL-17 monoclonal antibody; Secukinumab; IL-35 gene; Hepatoma; Invasive migration; Notch signaling pathway

\section{INTRODUCTION}

Hepatoma, or liver cancer, is a common disease that can be divided into to two major categories: primary and secondary (Wang et al., 2010; Siegel et al., 2012). Primary hepatoma originates in the liver epithelial or mesenchymal tissue and is of high incidence and malignancy. Secondary hepatoma is called sarcoma and is relatively rare compared with primary hepatoma. Secondary or metastatic hepatoma is when the tumor originated from another organ, such as stomach, bile duct, pancreas, colorectal, ovarian, uterine, lunch or breast, and invades the liver. In China, liver cancer accounts for the first and second causes of mortality in the countryside and cities, respectively. The incidence of liver cancer in some developed cities in China is also increasing each year. In fact, the liver cancer incidence rate in some cities is higher than in some developed countries (Jemal et al., 2011). Although various treatment methods continue to improve, the mortality rate of the disease is still stubbornly high, which is mainly caused by the high rates of recurrence and metastasis. The process of hepatoma cell metastasis is mostly through invasion and migration (Cano et al., 2000; Comijn et al., 2001).

Therefore, there is an urgent need for new treatment methods. Since the late 20th century, the study of tumor genes has made remarkable progress. Many tumor suppressor genes and carcinogenic genes have been identified, thus promoting the achievement in genetic screening and targeted therapy. In this study, we examined the newly discovered cytokine interleukin (IL)-35 (Collison et al., 2007; Duelund et al., 2012) with immune-modulatory functions, combined with the carcinogenic cytokine IL-17 monoclonal antibody Secukinumab, on the treatment of liver cancer (Stern et al., 1990; Niedbala et al., 2007; Nam et al., 2008). In this study, we screened stable cell lines containing IL-35 genes and used Secukinumab to stabilize the cell line. We then investigated the synergistic effects of the combination on hepatoma cell proliferation, invasion, and apoptosis, thus also providing experimental evidence for the treatment of hepatoma cell. The focus of this study is whether this combinatorial treatment can inhibit the metastasis of hepatoma cells.

\section{MATERIAL AND METHODS}

\section{Cell lines and reagents}

Normal non-tumor liver cell line HL-7702, hepatoma cell line HepG2 (SMMC-7721), 
and $\mathrm{MHCC} 97 \mathrm{H}$ are all frozen cell lines from Sun Yat-sen University, China. The following reagents were also used: IL-17 monoclonal antibody Secukinumab (Novartis, Basle, Switzerland); IL-35 gene (Diagnostic Systems Laboratorie, USA); DMEM culture medium (BD Biosciences, USA); fetal bovine serum (BD Biosciences); TRIzol reagent (BD Biosciences); Primescript reverse transcription (RT) reagent Kit (TaKaRa, Tokyo, Japan) SYBR Premix Ex Taq TM II (Perfect Real Time) kit (Sigma, USA); BCA protein quantitative kit (Sigma); mouse anti-human N1ICD antibody (Abcam Inc., London, UK); mouse anti-human GAPDH antibody (BD Biosciences); rabbit anti-human Snail antibody (BD Biosciences); goat antihuman E-cadherin antibody (BD Biosciences); DNA marker (Sigma); and DNA loading buffer (Sigma).

\section{Cell culture}

Hepatoma cell lines (HepG2, SMMC-7721, MHCC97H) and normal non-tumor cell line (HL-7702) were cultured in $100 \mathrm{~mL} / \mathrm{L}$ fetal bovine serum DMEM culture medium (containing penicillin $100 \mathrm{kU} / \mathrm{L}$, streptomycin $100 \mu \mathrm{g} / \mathrm{mL}$ ) under $37^{\circ} \mathrm{C}, 50 \mathrm{~mL} / \mathrm{L} \mathrm{CO}_{2}$, and saturated humidity environment for continuous culture. In the logarithmic growth phase, cells were harvested for the experiment and divided into four groups: A, non-treatment as the comparison group; B, IL-35 treated group; C, $4 \mu \mathrm{g} / \mathrm{mL}$ IL-17 monoclonal antibody Secukinumab treated group; and $\mathrm{D}, 4 \mu \mathrm{g} / \mathrm{mL}$ IL-17 monoclonal antibody Secukinumab combined with IL-35 treated group.

\section{Real-time quantitative polymerase chain reaction (PCR) to measure expression of Hes1, Hes5 and Hey1}

All cells were cultured under normal conditions then $1 \mathrm{~mL}$ Trizol Reagent was added and mixed. Next, $0.2 \mathrm{~mL}$ chloroform was added, the mixture was shaken, and then put in an ice bath for $5 \mathrm{~min}$. The mixture was centrifuged for $20 \mathrm{~min}$ at $4^{\circ} \mathrm{C}$ and $12,000 \mathrm{rpm}$, the supernatant was decanted, and an equal amount of isopropanol was added. After incubation in an ice bath for $5 \mathrm{~min}$ and centrifugation for $20 \mathrm{~min}$ at $4^{\circ} \mathrm{C}$ and $12,000 \mathrm{rpm}$. The supernatant was discarded and $1 \mathrm{~mL} \mathrm{75 \%}$ ethanol was added, shaken sufficiently to make the RNA dissolve, and then centrifuged for $5 \mathrm{~min}$ at $4^{\circ} \mathrm{C}$ and $10,000 \mathrm{rpm}$. The supernatant was carefully removed then the tube was turned upside down and dried for $15 \mathrm{~min}$ at room temperature. When the pellet was dry, $20 \mu \mathrm{L}$ RNase-free water was added to dissolve the RNA. One microliter was kept and the rest was stored at $-70^{\circ} \mathrm{C}$. The $1 \mu \mathrm{L}$ that was kept was diluted in $80 \mu \mathrm{L}$ water to measure the ratio of $\mathrm{OD}_{260}$ to $\mathrm{OD}_{280}$ on a spectrophotometer to calculate the total RNA. To synthesize cDNA, reverse transcription was performed using PrimeScript RT reagent Kit according the manufacturer instructions (Code No. 9160). Briefly, five-fold PrimeScript Buffer $(2 \mu \mathrm{L})$, PrimeScript RT Enzyme Mix $(0.5 \mu \mathrm{L})$, total RNA $(2 \mu \mathrm{L})$, and RNase Free $\mathrm{H}_{2} \mathrm{O}(5 \mu \mathrm{L})$ were combined (total $10 \mu \mathrm{L}$ ) and put at $37^{\circ} \mathrm{C}$ water bath for 15 min then at $85^{\circ} \mathrm{C}$ for $15 \mathrm{~s}$.

After the reverse transcription, the appropriate amount of synthesized cDNA was used to conduct real-time fluorescence quantitative PCR and the rest was stored at $-20^{\circ} \mathrm{C}$ for further study. The real-time PCR was conducted according to the manufacturer instructions using the SYBR Premix Ex Taq TM II (Code No. RR041A) kit. Briefly, SYBR Premix Ex Taq (12.5 $\mu \mathrm{L}), \mathrm{PCR}$ forward primer $(1 \mu \mathrm{L}), \mathrm{PCR}$ reverse primer $(1 \mu \mathrm{L})$, DNA template $(2 \mu \mathrm{L})$, and $\mathrm{H}_{2} \mathrm{O}$ 
$(8.5 \mu \mathrm{L})$ were combined in a total of $25 \mu \mathrm{L}$. Real-time PCR was performed as follows: the amplification curve, pre-denaturation at $95^{\circ} \mathrm{C}$ for $5 \mathrm{~min}$, denaturation at $95^{\circ} \mathrm{C}$ for $20 \mathrm{~s}$, annealing at $60^{\circ} \mathrm{C}$ for $30 \mathrm{~s}$, and extension for $20 \mathrm{~s}$ at $72^{\circ} \mathrm{C}$. The final stage is when the acquisition of fluorescence signal was obtained in a total of 40 cycles. The melting curve was performed at $60^{\circ} \mathrm{C}$ to $\sim 95^{\circ} \mathrm{C}$ in $0.5^{\circ} \mathrm{C}$ increasing increments in temperature at each cycle for $20 \mathrm{~s}$. The fluorescence signal was acquired in a total of 71 cycles. To measure the PCR products, they were examined on $1 \%$ agarose gels for electrophoresis. The Hes1, Hes5, Hey1 and GAPDH sequence primers are as follows: Hes1: forward, 5'-AGGCGGACATTCTGGAAATG-3', reverse, 5'-TCGTTCATGCACTCGCTGA-3'; Hes5: forward, 5'-ACCGCATCAACAGCAGCA TT-3', reverse, 5'-AGGCTTTGCTGTGCTTCAGGT-3'; Hey1: forward, 5'-AACTGTTGGTG GCCTGAATC-3', reverse, 5'-GCGGTAAATGCAGGCGTAT-3'; and GAPDH: forward, 5'-AAATCCCATCACCATCTTCC-3', reverse, 5'-TCACACCCATGACGAACA-3'.

\section{Protein expression of N1ICD and Snail/ E-cadherin using western blot}

The HepG2, SMMC-7721, MHCC97H, and normal non-tumor HL-7702 cell lines were collected, washed with PBS twice, and $400 \mu \mathrm{L}$ cell lysis buffer and $40 \mu \mathrm{L}$ PMSF were added. The culture flasks were shaken gently, put on ice for 10 minutes, repeatedly aspired with a sterile syringe, and incubated on ice for another $30 \mathrm{~min}$. Following this, the samples were centrifuged at $12,000 \mathrm{~g}$ for 15 minutes, the supernatant decanted into another tube, and $20 \mu \mathrm{L}$ protein sample buffer was added for every $100 \mu \mathrm{L}$ of sample. The mixture was boiled for $5 \mathrm{~min}$, mixed, and stored at $-80^{\circ} \mathrm{C}$ for further use. The above samples were run on $12 \%$ SDS-PAGE to separate proteins and transferred to a PVDF membrane. The primary antibody was added (1:1000 dilution) and incubated overnight at $4^{\circ} \mathrm{C}$. After washing, the secondary antibody was added (BA1026; 1:1000 dilution) and incubated for $1 \mathrm{~h}$. After washing, the blot was visualized using chemiluminescence reagent for chromogenic developing and fixing. The protein expression of N1ICD and Snail/E-cadherin was then measured.

\section{Detection of cell invasion and migration}

Using Transwell plates coated with Matrigel, all cells were collected from each group, resuspended in serum-free DMEM culture medium, starved for $24 \mathrm{~h}$, and then the cell density was adjusted to $1 \times 10^{5} / \mathrm{mL}$. The upper chambers were inoculated with $200 \mu \mathrm{L}$ cell suspension and $600 \mu \mathrm{L}$ DMEM culture medium containing $20 \%$ fetal bovine serum was added on 24 -well plates, then the Transwell chamber was inserted into the plates and incubated conventionally for $24 \mathrm{~h}$. The Transwell chamber was removed, gently washed with $0.01 \mathrm{M}$ PBS, and the interior adherent cells were removed using cotton swabs. The remaining cells were then fixed in $95 \%$ ethanol and stained with crystal violet. The cells were observed under an inverted microscope and 5 randomly selected views were observed (200X) to examine the number of invaded cells. The mean value was calculated from the experiment repeated in triplicate for all four groups. The same method was performed for migration analysis.

\section{Statistical analysis}

Each experiment was repeated three times and compared using the one-way ANOVA 
Bonferroni test in SPSS13.0 (Chicago, IL, USA) to do pairwise comparison in multiple samples. $\mathrm{P}<0.05$ was taken to mean significant difference.

\section{RESULTS}

\section{Invasive migration capabilities of different hepatoma cell lines and the normal non-tumor cell line}

In this study, we selected different hepatoma cell lines (HepG2, SMMC-7721, MHCC97H) and one non-tumor cell line (HL-702). Use Transwell chambers, we assessed the invasive migration capabilities of the above cell lines. The results show that the invasive migration capability of hepatoma cell lines was significantly higher than that of normal nontumor liver cells (Figure 1). In addition, the hepatoma cell lines exhibited differences in migration capability, with HepG2 exhibiting the lowest migration and MHCC97H having the highest (Figure 1).

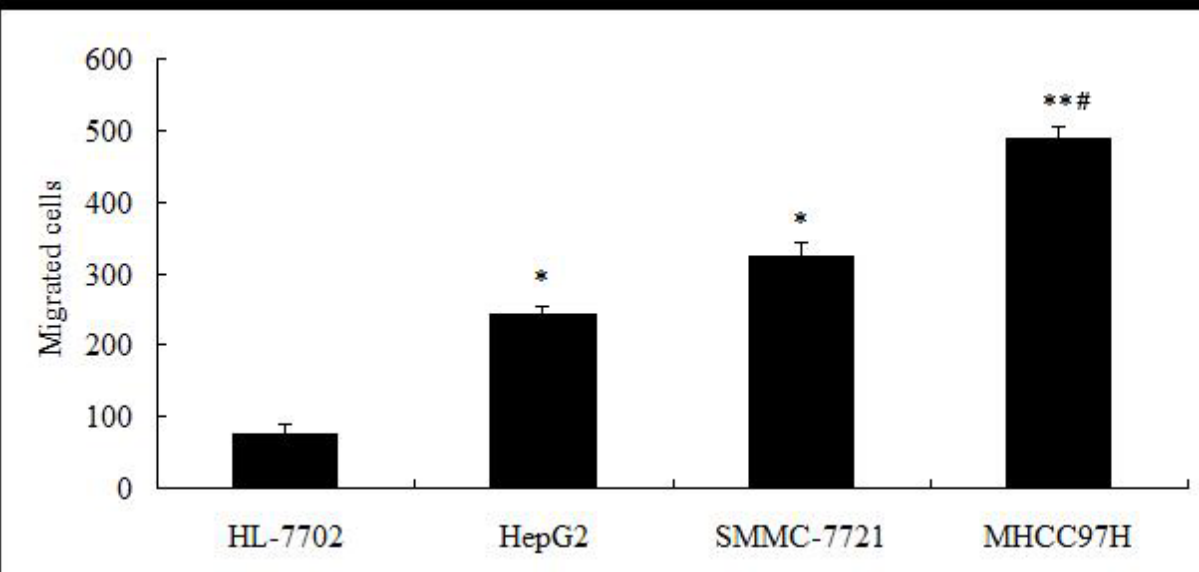

Figure 1. Invasive migration capabilities of different hepatoma cell lines. $* * \mathrm{P}<0.01$ vs HL-7702 group; ${ }^{\mathrm{P}}<0.05$ vs HL-7702 group; $\mathrm{P}<0.05$ vs HepG2 group.

\section{Effect of IL-17 monoclonal antibody Secukinumab combined with IL-35 on cell invasive migration capabilities of hepatoma cell lines}

We used Transwell chambers coated with Matrigel to assess invasive migration capabilities of different cell lines and compare them with the non-treated group. The combined treatment of IL-17 antibody and IL-35 can effectively inhibit invasive cell migration in HepG2, SMMC-7721 and MHCC97H cells (Tables 1 and 2).

\section{Detecting the expression of Hes1, Hes5 and Hey1 by quantitative PCR}

Using quantitative PCR, we detected the classic downstream genes of the Notch signaling pathway, namely Hes1, Hes5 and Hey1 (Figure 2). Compared with the HL-7702 
Table 1. Effect of IL-17 monoclonal antibody Secukinumab combined with IL-35 gene on cell invasion capabilities of HepG2, SMMC-7721, and MHCC97H.

\begin{tabular}{l|c|c|c}
\hline \multicolumn{3}{|c}{ Invaded cells } \\
\hline Group & HepG2 & MHCC97H & SMMC-772 \\
\hline A & $278.12 \pm 15.83$ & $521.02 \pm 20.06$ & $412.93 \pm 14.49$ \\
\hline B & $167.34 \pm 12.09^{*}$ & $324.35 \pm 12.00^{*}$ & $268.03 \pm 13.83^{*}$ \\
\hline C & $112.67 \pm 9.09^{* *}$ & $187.62 \pm 12.83^{* * \#}$ & $178.22 \pm 5.92^{* * \#}$ \\
\hline D & $45.93 \pm 3.22^{* * \# \& \&}$ & $34.81 \pm 2.09^{* * \# \# \& \&}$ & $32.91 \pm 6.99^{* * \# \&}$ \\
\hline
\end{tabular}

** $\mathrm{P}<0.01$ vs A group, ${ }^{*} \mathrm{P}<0.05$ vs A group, ${ }^{\#} \mathrm{P}<0.01$ vs $\mathrm{B}$ group, ${ }^{*} \mathrm{P}<0.05$ vs $\mathrm{B}$ group, ${ }^{\text {\&\& }} \mathrm{P}<0.01$ vs $\mathrm{C}$ group, ${ }^{\&} \mathrm{P}<0.05$ vs $\mathrm{C}$ group. A, non-medicated comparison group; B, IL-35 gene medicated group; C, $4 \mu \mathrm{g} / \mathrm{mL}$ IL17 monoclonal antibody Secukinumab medicated group; D, $4 \mu \mathrm{g} / \mathrm{mL}$ IL-17 monoclonal antibody Secukinumab combined with IL-35 gene mediated group.

Table 2. Effects of IL-17 monoclonal antibody Secukinumab combined with IL-35 gene on the cell migration capabilities of HepG2 and SMMC-7721, and MHCC97H.

\begin{tabular}{l|c|c|c}
\hline \multicolumn{3}{|c}{ Migrated cells } \\
\hline Group & HepG2 & MHCC97H & SMMC-772 \\
\hline A & $301.23 \pm 19.23$ & $421.99 \pm 14.11$ & $398.87 \pm 19.23$ \\
\hline B & $212.56 \pm 17.02$ & $298.11 \pm 11.91$ & $203.12 \pm 12.35^{*}$ \\
\hline C & $132.87 \pm 12.98^{* \#}$ & $202.12 \pm 7.73^{* \#}$ & $122.77 \pm 10.32^{* \#}$ \\
\hline D & $56.02 \pm 7.23^{* * \# \&}$ & $43.23 \pm 2.82^{* * \# \&}$ & $54.90 \pm 7.92^{* * \# \# \&}$ \\
\hline
\end{tabular}

** $\mathrm{P}<0.01$ vs A group, $* \mathrm{P}<0.05$ vs A group, ${ }^{\#} \mathrm{P}<0.01$ vs $\mathrm{B}$ group, ${ }^{*} \mathrm{P}<0.05$ vs $\mathrm{B}$ group, ${ }^{\&}$ \& $\mathrm{P}<0.01$ vs $\mathrm{C}$ group, ${ }^{\&} \mathrm{P}<0.05$ vs $\mathrm{C}$ group. A, non-medicated comparison group; B, IL-35 gene medicated group; C, $4 \mu \mathrm{g} / \mathrm{mL}$ IL17 monoclonal antibody Secukinumab medicated group; D, $4 \mu \mathrm{g} / \mathrm{mL}$ IL-17 monoclonal antibody Secukinumab combined with IL-35 gene mediated group.

cells, the amount of Hes1, Hes5 and Hey1 in hepatoma cell lines was significantly increased, and their expression increased along with the hepatoma cell invasive migration capabilities. In the low invasive migration cells (HepG2), the expression of Hes1, Hes5 and Hey1 are the lowest; while in the high invasive migration cells $(\mathrm{MHCC} 97 \mathrm{H})$, the expression of Hes1, Hes5, Hey1 and N1ICD are the highest. Therefore, the relationship is positively proportional. The results suggest that the Notch signaling pathway is activated in hepatoma cells, and that activation is correlated with invasive migration capabilities, indirectly showing that the Notch signaling pathway is involved in the invasion and migration process of hepatoma cells.

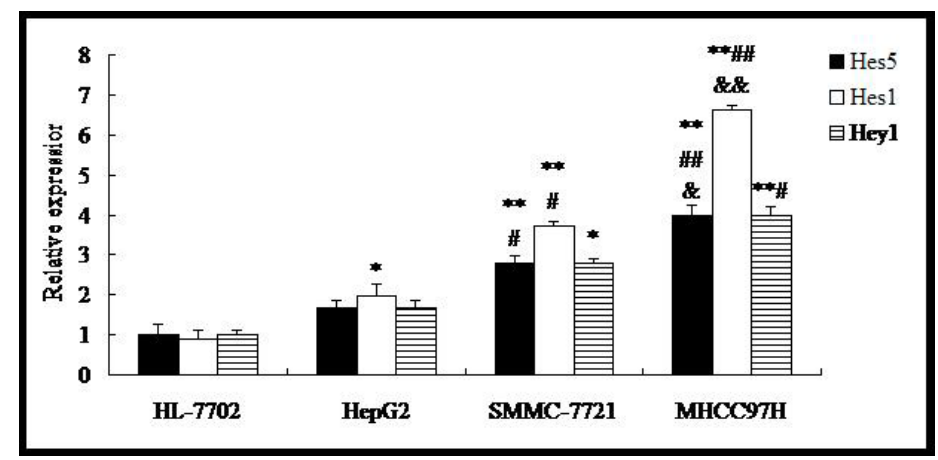

Figure 2. Expressions of Hes1, Hes5 and Hey1 using PCR method. **P $<0.01$ vs HL-7702 group; $* \mathrm{P}<0.05$ vs HL-7702 group; ${ }^{\#} \mathrm{P}<0.01$ vs HepG2 group; ${ }^{\#} \mathrm{P}<0.05$ vs HepG2 group; ${ }^{\&} \mathrm{P}<0.05$ vs $\mathrm{SMMC}-7721$ group; ${ }^{\&} \mathrm{P}<$ 0.01 vs $\mathrm{C}$ group. 


\section{Effects of IL-17 monoclonal antibody Secukinumab combined with IL-35 on the protein expression of Hes1 Hes5, and Hey1}

Again we used quantitative PCR to detect the downstream genes of the Notch signaling pathway (Hes1, Hes5, and Hey1). Compared with the non-treated group, treatment with IL-17 monoclonal antibody Secukinumab combined with IL-35 can effectively inhibit the expression of Hes1, Hes5, and Hey1 (Figure 3).

A

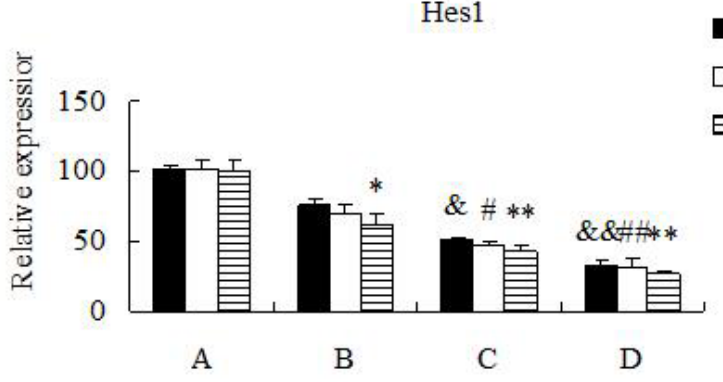

B

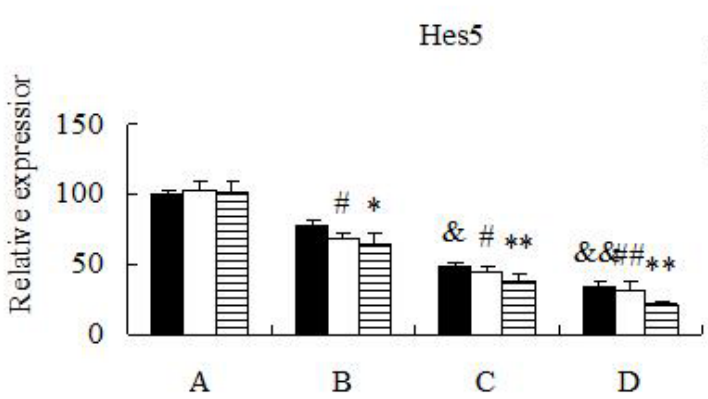

C

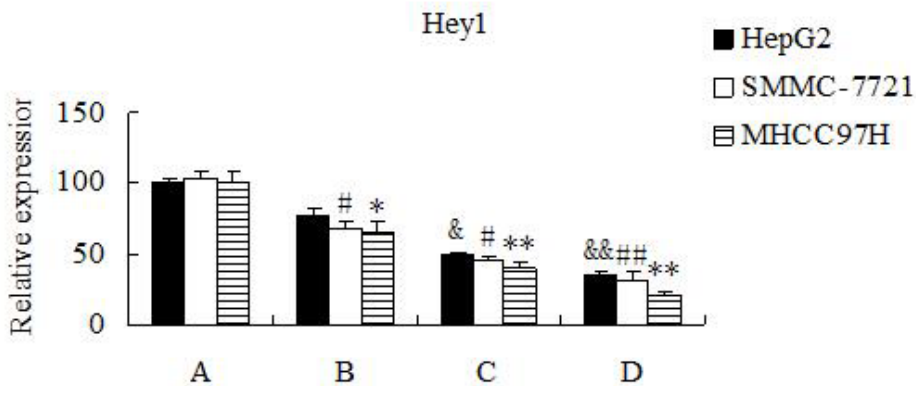

HepG2

$\square$ SMMC- 7721

$\boxminus \mathrm{MHCC} 97 \mathrm{H}$
- HepG2

$\square$ SMMC-7721

目 $\mathrm{MHCC} 97 \mathrm{H}$

Figure 3. Effects of IL-17 monoclonal antibody Secukinumab combined with IL-35 gene on the protein expressions of Hes1 Hes5, and Hey1. A. Non-medicated comparison group, ${ }^{* *} \mathrm{P}<0.01$ vs A group, ${ }^{*} \mathrm{P}<0.05$ vs A group, ${ }^{*} \mathrm{P}<$ 0.01 vs $\mathrm{B}$ group, ${ }^{*} \mathrm{P}<0.05$ vs $\mathrm{B}$ group, ${ }^{\&} \mathrm{P}<0.01$ vs $\mathrm{C}$ group, ${ }^{\& \&} \mathrm{P}<0.05$ vs $\mathrm{C}$ group; B. IL-35 gene medicated group; $\mathrm{C}, 4 \mu \mathrm{g} / \mathrm{mL}$ IL-17 monoclonal antibody Secukinumab medicated group, $* * \mathrm{P}<0.01$ s $\mathrm{A}$ group, $* \mathrm{P}<0.05$ vs $\mathrm{A}$ group, ${ }^{\#} \mathrm{P}<0.01$ vs $\mathrm{B}$ group, ${ }^{\#} \mathrm{P}<0.05$ vs $\mathrm{B}$ group, ${ }^{\& \&} \mathrm{P}<0.05$ v $\mathrm{C}$ group; $\mathrm{C} .4 \mu \mathrm{g} / \mathrm{mL}$ IL-17 monoclonal antibody Secukinumab combined with IL-35 gene mediated group $* * \mathrm{P}<0.01$ vs A group $* \mathrm{P}<0.05$ vs A group, ${ }^{\#} \mathrm{P}<0.01$ vs $\mathrm{B}$ group, ${ }^{\#} \mathrm{P}<0.05$ vs $\mathrm{B}$ group, ${ }^{\circledR} \mathrm{P}<0.01$ vs $\mathrm{C}$ group, ${ }^{\&} \mathrm{P}<0.05$ vs $\mathrm{C}$ group. 


\section{Detection of the expression of N1ICD in the hepatoma and normal cell lines using} western blot

The expression of the protein N1ICD was measured by western blot. Compared with the HL-7022 cell line, the expression of N1ICD in hepatoma cell lines was significantly increased and positively correlated with the hepatoma cell invasive migration capabilities. In the low invasive migration cell line HepG2, the expression of N1ICD was the lowest. In the highest invasive migration cell line MHCC97H, the expression of N1ICD was the highest (Figure 4).
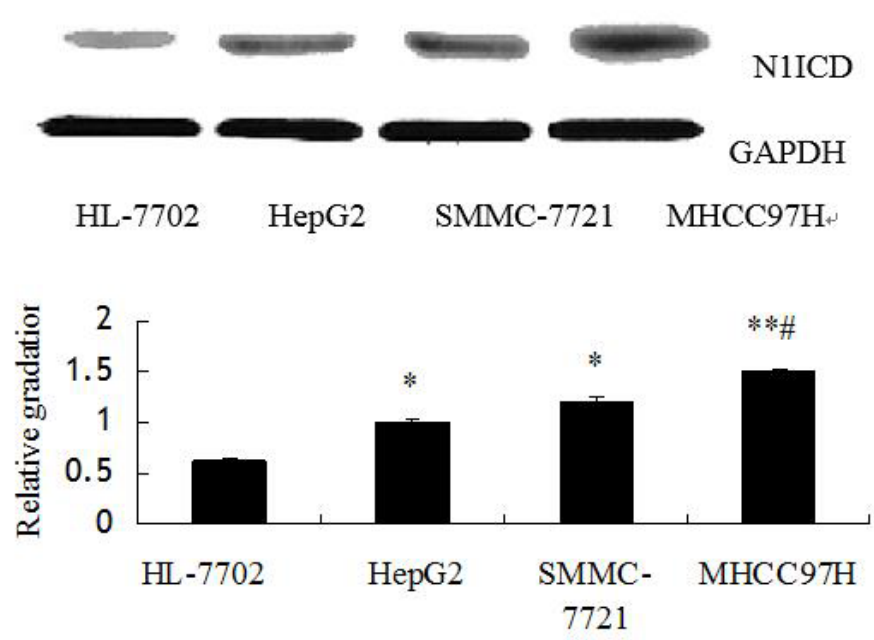

Figure 4. Expressions of protein N1ICD in the HL-7702, HepG2 and SMMC-7721, MHCC97H Cells using WB. $* * \mathrm{P}<0.01$ vs HL-7702 group, ${ }^{*} \mathrm{P}<0.05$ vs HL-7702 group, ${ }^{\sharp} \mathrm{P}<0.05$ vs HepG2 group.

\section{Detection of expression of N1ICD after treatment with IL-17 monoclonal antibody} Secukinumab combined with IL-35 using western blot

Using western blot, we measured the expression of N1ICD and used the non-treated group as the control. IL-17 monoclonal antibody Secukinumab combined with IL-35 can effectively inhibit the expression of N1ICD (Figure 5).

\section{Detection of the expression of Snail and E-cadherin in hepatoma cell lines by western blot}

The expression of Snail and E-cadherin in hepatoma cell lines was measured by western blot. Compared with the HL-7022 cell line, the expression of Snail in hepatoma cell lines was significantly increased and positively correlated with the invasive migration capabilities of hepatoma cells (Figure 6). However, the expression of E-cadherin protein was substantially lower and negatively correlated with the invasive migration capabilities of hepatoma cells. 

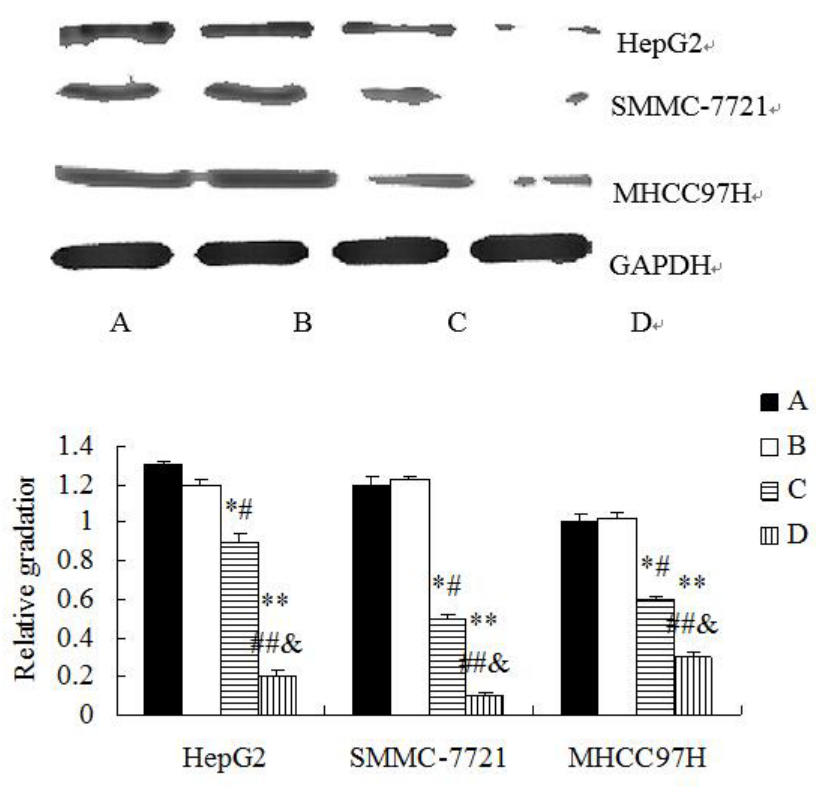

Figure 5. Expression of N1ICD after medicated by IL-17 monoclonal antibody Secukinumab combined with IL-35 gene using Western Blot method. A, non-medicated comparison group; B, IL-35 gene medicated group; C, $4 \mu \mathrm{g} / \mathrm{mL}$ IL-17 monoclonal antibody Secukinumab medicated group; D, $4 \mu \mathrm{g} / \mathrm{mL}$ IL-17 monoclonal antibody Secukinumab combined with IL-35 gene mediated group. ${ }^{*} * \mathrm{P}<0.01$ vs A group, ${ }^{*} \mathrm{P}<0.05$ vs A group, ${ }^{\#} \mathrm{P}<0.01$ vs $\mathrm{B}$ group, ${ }^{*} \mathrm{P}<0.05$ vs $\mathrm{B}$ group, ${ }^{\&} \mathrm{P}<0.05$ vs $\mathrm{C}$ group.
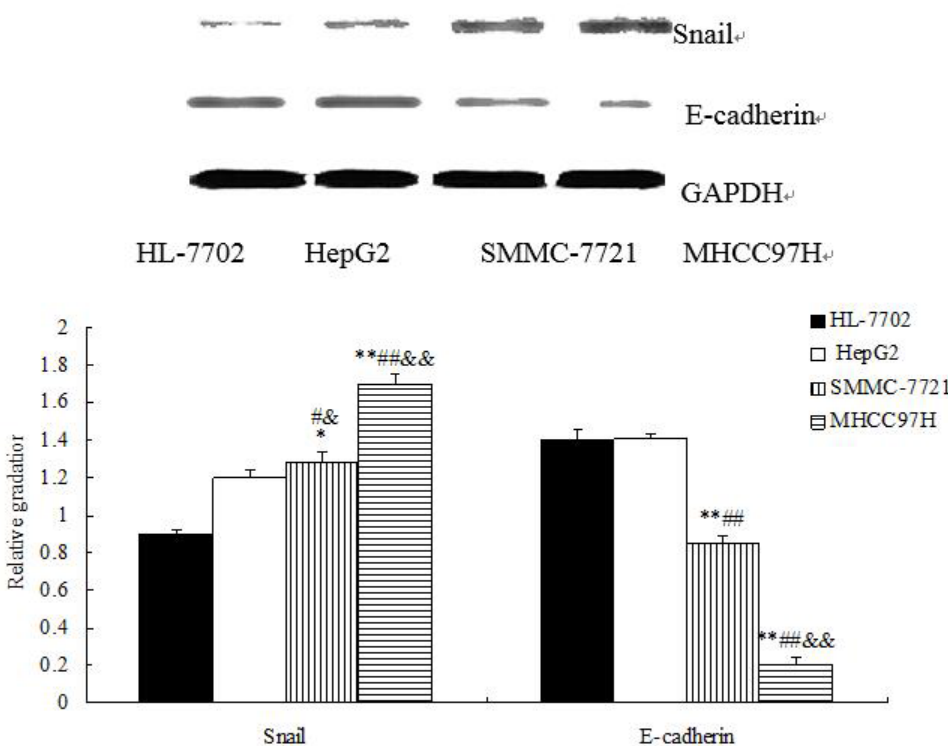

Figure 6. Expressions of Snail and E-cadherin in different cells. $* * \mathrm{P}<0.01$ ss HL-7702 group, $* \mathrm{P}<0.05$ vs HL7702 group, ${ }^{\#} \mathrm{P}<0.01$ vs HepG2 group, ${ }^{\#} \mathrm{P}<0.05$ vs HepG2 group, ${ }^{\&} \mathrm{P}<0.05$ vs $\mathrm{SMMC}-7721$ group; ${ }^{\& \&} \mathrm{P}<0.01$ vs $\mathrm{C}$ group. 


\section{Detection of the expression of Snail and E-cadherin after treatment with IL-17 monoclonal antibody Secukinumab combined with IL-35 by western blot}

Following treatment with the IL-17 monoclonal antibody Secukinumab combined with IL-35, the Snail and E-cadherin protein expression in the hepatoma cell lines HepG2, SMMC-7721, and MHCC97H was detected by western blot. Compared with the non-treated group, the combined treatment substantially decreased the expression of Snail in HepG2, SMMC-7721, and MHCC97H cell lines (Figure 7). However, the expression of E-cadherin was increased after treatment.

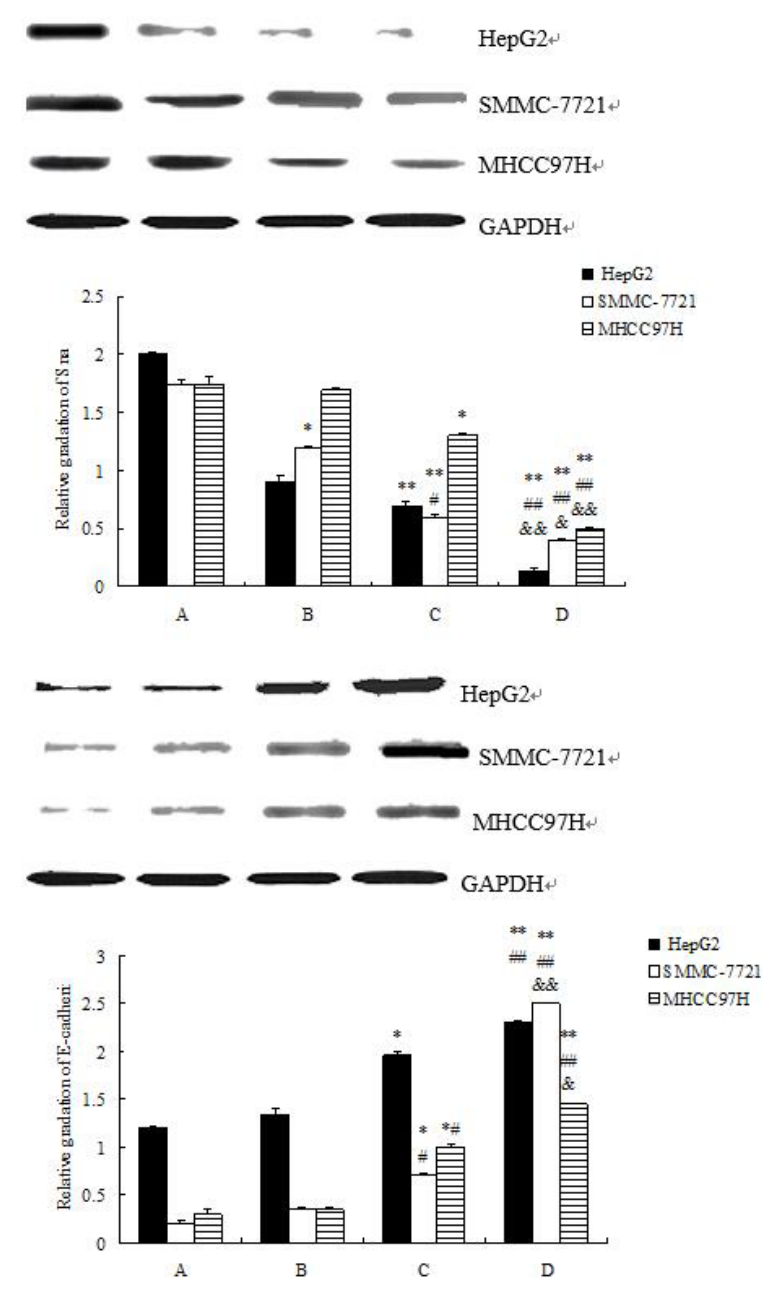

Figure 7. Expression of Snail and E-cadherin after the medication of the IL-17 monoclonal antibody Secukinumab combined with the IL-35 gene. ${ }^{* *} \mathrm{P}<0.01$ vs A group, ${ }^{*} \mathrm{P}<0.05$ vs A group, ${ }^{\#} \mathrm{P}<0.01$ vs $\mathrm{B}$ group, ${ }^{\#} \mathrm{P}<0.05$ vs $\mathrm{B}$ group, ${ }^{\&} \mathrm{P}<0.05$ vs $\mathrm{C}$ group; ${ }^{\&}{ }^{\&} \mathrm{P}<0.01$ vs $\mathrm{C}$ group. $\mathrm{A}$, non-medicated comparison group; $\mathrm{B}$, IL-35 gene medicated group; C, $4 \mu \mathrm{g} / \mathrm{mL}$ IL-17 monoclonal antibody Secukinumab medicated group; D, $4 \mu \mathrm{g} / \mathrm{mL}$ IL-17 monoclonal antibody Secukinumab combined with IL-35 gene mediated group. 
Invasive capability of hepatoma cells

\section{DISCUSSION}

Liver cancer is a highly lethal malignant tumor, especially in China where there is a high incidence of hepatitis. Along with the development of more advanced medical technologies, there are more treatment methods for hepatoma. However, due to the relatively common metastasis of hepatoma, the overall prognosis is not very good. Presently, the treatment of hepatoma is partly focused on the metastasis process, which includes both invasion and migration processes (Yoshitani et al., 2001; Thamilselvan et al., 2011). Therefore, it would be imperative to the treatment of liver cancer if we understand the mechanisms of invasion and migration.

Currently, the IL-17 monoclonal antibody Secukinumab is employed as the gene antibody of most targeted therapies. Secukinumab is a new highly specific human immunoglobulin $\mathrm{G}(\mathrm{IgG})$ monoclonal antibody, which can bind and neutralize human IL-17 and block the IL-17 pathway. Currently, Secukinumab is mainly used for the treatment of rheumatoid arthritis, ankylosing spondylitis, and plaque psoriasis (Hueber et al., 2010; Papp, 2011). However, there are rare reports on its use in the treatment of cancer.

The Notch signaling pathway is traditional with a conservative structure. As research progresses, we find that the Notch signaling pathway is involved not only in the development of individual organisms, but also in the genesis and development of tumors. Therefore, understanding the mechanism of Notch in the invasive migration process is conducive to both the study of its physiological role and its new perspective role in hepatoma treatment (Qi et al., 2003; Cantarini et al., 2006; Huang et al., 2007; Gao et al., 2008). In this study, we found that the Notch signaling pathway is activated in hepatoma cells and increases with the enhancement of invasive migration capabilities, which means that Notch is involved in the process of hepatoma cell invasive migration. Our experiments show that IL-17 antibody combined with IL-35 can effectively inhibit the Notch signaling pathway, and the inhibitory effect increased substantially with an increasing dose of combined treatment. We employed different concentrations of IL-17 antibody combined with IL-35 to block the Notch signaling pathway, and found that the expression of Hes1, Hes5, Hey1 and N1ICD are high in hepatoma cell lines and positively correlated with hepatoma cell invasive migration capabilities. This explains the fact that the Notch signaling pathway is activated in hepatoma cell lines and increases with cell invasive migration capabilities. Therefore, blocking the Notch signaling pathway can inhibit the invasive migration capabilities of hepatoma cells.

The metastasis of tumor cells cannot be ignored and reduction of the adhesion between cells plays a significant role (Soler et al., 1997). In the metastasis of hepatoma cells, the change of cell adhesion is closely related with the expression of surface adhesion molecules. Of all these adhesion molecules, cadherin, particularly E-cadherin, is a major player. It is a calcium-dependent transmembrane glycoprotein that is mainly involved in intercellular adhesion (Inayoshi et al., 2003). As an important cell adhesion molecule, its expression is negatively correlated with the genesis and development of tumors. As an upstream molecule of E-cadherin, Snail is capable of inhibiting the expression of the E-cadherin gene (Chen et al., 2007). However, in our study of the tumor invasive migration process, Snail and E-cadherin are seen as both being involved. The low expression of E-cadherin in hepatoma cells is the cause of the drop in adhesion, in which the hepatoma cells easily detach from the primary lesion and extra-hepatic metastasis occurs (Wei et al., 2002). This means the decline in E-cadherin protein expression is an indicator of this detachment process. In this study, the treatment of IL- 
17 antibody combined with IL-35 can block the Notch signaling pathway, and the expression of Snail decreases as the expression of E-cadherin increases. As the treatment dose increased, the Snail expression further declines and E-cadherin expression further increases, leading to a decrease in the invasive migration capabilities of hepatoma cells. In this mechanism, the Notch signaling pathway regulates metastasis through the Snail/E-cadherin pathway.

The IL-17 monoclonal antibody Secukinumab combined with IL-35 can block the Notch signaling pathway through the Snail/E-cadherin pathway, which can influence the invasive migration capabilities of hepatoma cell lines.

\section{Conflicts of interest}

The authors declare no conflict of interest.

\section{REFERENCES}

Cano A, Pérez-Moreno MA, Rodrigo I, Locascio A, et al. (2000). The transcription factor snail controls epithelialmesenchymal transitions by repressing E-cadherin expression. Nat. Cell Biol. 2: 76-83. http://dx.doi. org $/ 10.1038 / 35000025$

Cantarini MC, de la Monte SM, Pang M, Tong M, et al. (2006). Aspartyl-asparagyl beta hydroxylase over-expression in human hepatoma is linked to activation of insulin-like growth factor and notch signaling mechanisms. Hepatology 44: 446-457. http://dx.doi.org/10.1002/hep.21272

Chen XJ, Wu LM, Xu XB, Feng XW, et al. (2007). [Expression and prognostic value of Polo-like kinase 1, E-cadherin in the patients with hepatocellular carcinoma]. Zhonghua Wai Ke Za Zhi 45: 1354-1358.

Collison LW, Workman CJ, Kuo TT, Boyd K, et al. (2007). The inhibitory cytokine IL-35 contributes to regulatory T-cell function. Nature 450: 566-569. http://dx.doi.org/10.1038/nature06306

Comijn J, Berx G, Vermassen P, Verschueren K, et al. (2001). The two-handed E box binding zinc finger protein SIP1 downregulates E-cadherin and induces invasion. Mol. Cell 7: 1267-1278. http://dx.doi.org/10.1016/S10972765(01)00260-X

Duelund L, Amiot A, Fillon A and Mouritsen OG (2012). Influence of the active compounds of Perilla frutescens leaves on lipid membranes. J. Nat. Prod. 75: 160-166. http://dx.doi.org/10.1021/np200713q

Gao J, Song Z, Chen Y, Xia L, et al. (2008). Deregulated expression of Notch receptors in human hepatocellular carcinoma. Dig. Liver Dis. 40: 114-121. http://dx.doi.org/10.1016/j.dld.2007.08.001

Huang J, Zhang X, Zhang M, Zhu JD, et al. (2007). Up-regulation of DLK1 as an imprinted gene could contribute to human hepatocellular carcinoma. Carcinogenesis 28: 1094-1103. http://dx.doi.org/10.1093/carcin/bgl215

Hueber W, Patel DD, Dryja T, Wright AM, et al.; Psoriasis Study Group; Rheumatoid Arthritis Study Group; Uveitis Study Group (2010). Effects of AIN457, a fully human antibody to interleukin-17A, on psoriasis, rheumatoid arthritis, and uveitis. Sci. Transl. Med. 2: 52ra72. http://dx.doi.org/10.1126/scitranslmed.3001107

Inayoshi J, Ichida T, Sugitani S, Tsuboi Y, et al. (2003). Gross appearance of hepatocellular carcinoma reflects E-cadherin expression and risk of early recurrence after surgical treatment. J. Gastroenterol. Hepatol. 18: 673-677. http://dx.doi. org/10.1046/j.1440-1746.2003.03021.x

Jemal A, Bray F, Center MM, Ferlay J, et al. (2011). Global cancer statistics. CA Cancer J. Clin. 61: 69-90. http://dx.doi. org/10.3322/caac. 20107

Nam JS, Terabe M, Kang MJ, Chae H, et al. (2008). TGF-B subverts the immune system into directly promoting tumor growth through IL-17. Cancer Res. 68: 3915-3923. http://dx.doi.org/10.1158/0008-5472.CAN-08-0206

Niedbala W, Wei XQ, Cai B, Hueber AJ, et al. (2007). IL-35 is a novel cytokine with therapeutic effects against collageninduced arthritis through the expansion of regulatory T cells and suppression of Th17 cells. Eur. J. Immunol. 37: 3021-3029. http://dx.doi.org/10.1002/eji.200737810

Papp KA (2011). Secukinumab efficacy and safety preliminary results from a phase II subcutaneous dose-ranging study in the treatment of moderate-to-severe plaque psoriasis. 20th Congress of the European Academy of Dermatology and Venereology, Lisbon, Portugal.

Qi R, An H, Yu Y, Zhang M, et al. (2003). Notch1 signaling inhibits growth of human hepatocellular carcinoma through induction of cell cycle arrest and apoptosis. Cancer Res. 63: 8323-8329. 
Siegel R, Naishadham D and Jemal A (2012). Cancer statistics, 2012. CA Cancer J. Clin. 62: 10-29. http://dx.doi. org/10.3322/caac. 20138

Soler AP, Harner GD, Knudsen KA, McBrearty FX, et al. (1997). Expression of P-cadherin identifies prostate-specificantigen-negative cells in epithelial tissues of male sexual accessory organs and in prostatic carcinomas. Implications for prostate cancer biology. Am. J. Pathol. 151: 471-478.

Stern AS, Podlaski FJ, Hulmes JD, Pan YC, et al. (1990). Purification to homogeneity and partial characterization of cytotoxic lymphocyte maturation factor from human B-lymphoblastoid cells. Proc. Natl. Acad. Sci. USA 87: 68086812. http://dx.doi.org/10.1073/pnas.87.17.6808

Thamilselvan V, Menon M and Thamilselvan S (2011). Anticancer efficacy of deguelin in human prostate cancer cells targeting glycogen synthase kinase-3 b/b-catenin pathway. Int. J. Cancer 129: 2916-2927. http://dx.doi.org/10.1002/ ijc. 25949

Wang Y, Lu Y, Toh ST, Sung WK, et al. (2010). Lethal-7 is down-regulated by the hepatitis B virus x protein and targets signal transducer and activator of transcription 3. J. Hepatol. 53: 57-66. http://dx.doi.org/10.1016/j.jhep.2009.12.043

Wei Y, Van Nhieu JT, Prigent S, Srivatanakul P, et al. (2002). Altered expression of E-cadherin in hepatocellular carcinoma: correlations with genetic alterations, beta-catenin expression, and clinical features. Hepatology 36: 692701. http://dx.doi.org/10.1053/jhep.2002.35342

Yoshitani SI, Tanaka T, Kohno H and Takashima S (2001). Chemoprevention of azoxymethane-induced rat colon carcinogenesis by dietary capsaicin and rotenone. Int. J. Oncol. 19: 929-939. 